\title{
Paediatric crossword puzzle 37
}

Manouri P Senanayake ${ }^{1,2}$, A S Athapathu ${ }^{2}$

Sri Lanka Journal of Child Health, 2017; 46(4): 391

DOI: http://dx.doi.org/10.4038/sljch.v46i4.8395

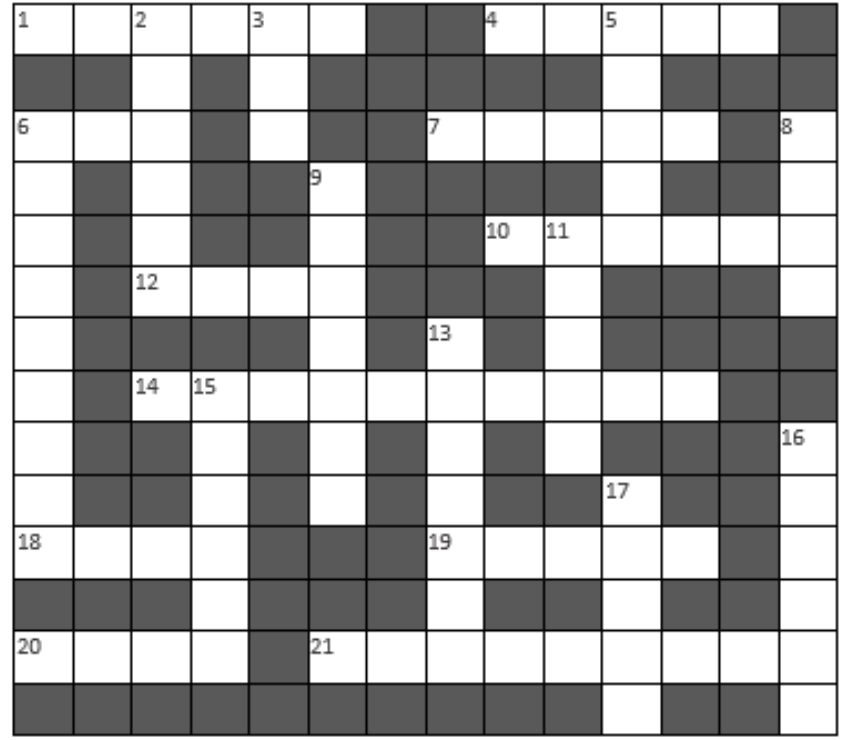

\section{ACROSS}

1. Screening needed on diagnosis of coeliac disease

4. Children with Angelman syndrome enjoy playing excessively with

6. Increases twin pregnancies

7. Effective treatment for nocturnal enuresis

10. Derogatory term originally derived from Latin word meaning 'Christian'

12. National Institute of Health and Care Excellence (abbrv)

14. Cause of recurrent chest infections in cerebral palsy

18. In-service course for all doctors involved in resuscitation of a child (abbrv) 19. Heart valve involvement in Noonan Syndrome is on side

20. Package used for data manipulation and analysis in research (abbrv)

21. Obesity is a side effect of

\section{DOWN}

2. Blueberry erythropoiesis

3. Term for child whose care has been taken over by the State (abbrv)

5. Latest Bayley Scales of infant and toddler development is termed version

6. Illness prevented by seasonal immunization

8. Skin condition treated with Minocycline

9. Immune mediated $\mathrm{GI}$ disease with genetic predisposition which affects small intestine

11. Thinking in Autism

13. Penicillin is the first antibiotic discovered

15. In paediatrics it is important to differentiate between infection and

16. Antigenic dietary item causing Coeliac Disease

17. A clinical feature uncommon in babies with whooping cough

${ }^{1}$ Department of Paediatrics, Faculty of Medicine, Colombo, ${ }^{2}$ Lady Ridgeway Hospital for Children, Colombo 